\title{
Autism Spectrum Disorders in Adult Outpatients with Obsessive Compulsive Disorder in the UK
}

\section{Maheshi Wikramanayake, William Mandy, Sonia Shahper, Sukhwinder Kaur, Sangeetha Kolli, Selma Osman, Jemma Reid, Kiri Jefferies_Sewell \& Naomi Fineberg}

To cite this article: Maheshi Wikramanayake, William Mandy, Sonia Shahper, Sukhwinder Kaur, Sangeetha Kolli, Selma Osman, Jemma Reid, Kiri Jefferies_Sewell \& Naomi Fineberg (2017): Autism Spectrum Disorders in Adult Outpatients with Obsessive Compulsive Disorder in the UK, International Journal of Psychiatry in Clinical Practice, DOI: 10.1080/13651501.2017.1354029

To link to this article: http://dx.doi.org/10.1080/13651501.2017.1354029

Accepted author version posted online: 14 Jul 2017.

\section{Submit your article to this journal \lceil}

LII Article views: 5

Q View related articles $₫$

View Crossmark data $₫$ 


\section{Title page}

Manuscript Title

Autism Spectrum Disorders in Adult Outpatients with Obsessive Compulsive Disorder in the UK

\section{Running title}

ASD in adults with OCD in the UK

\section{Contributing authors}

Maheshi Wikramanayake ${ }^{1,2}$, William Mandy ${ }^{3}$, Sonia Shahper ${ }^{2}$, Sukhwinder Kaur ${ }^{4}$, Sangeetha Kolli ${ }^{5}$, Selma Osman ${ }^{6}$, Jemma Reid ${ }^{4}$, Kiri Jefferies_Sewell ${ }^{2}$, Naomi Fineberg ${ }^{2,4}$

${ }^{1}$ Cambridge and Peterborough NHS Foundation Trust, Peterborough, UK.

${ }^{2}$ University of Hertfordshire, Hatfield, UK

${ }^{3}$ University College London, London, UK

${ }^{4}$ Hertfordshire Partnership University NHS Foundation Trust, Welwyn-Garden-City, UK

${ }^{5}$ East London Foundation NHS Trust, Bedford, UK

${ }^{6}$ Northumberland, Tyne \& Wear NHS Foundation Trust, Newcastle, UK

\section{Corresponding author}

Maheshi Wikramanayake, Cavell Centre, Edith Cavell Healthcare Campus, Bretton Gate, Peterborough, PE3 9GZ, UK.

Mobile: 004407725554294

maheshi@wikramanayake.com 


\section{Abstract}

\section{Background}

Patients with obsessive compulsive disorder (OCD) frequently show traits of autism spectrum disorders (ASD). This is one of the first studies to explore the clinical impact of the overlap between OCD and ASD as a categorical diagnosis.

\section{Methods}

A cross-sectional survey in 73 adult outpatients with DSM-IV OCD. Autistic traits were measured using the Autism-Spectrum Quotient (AQ). A clinical estimate ASD diagnosis was made by interview using DSM-IV-TR criteria. OCD patients with and without autistic traits or ASD were compared on demographic and clinical parameters and level of OCD treatmentresistance based on treatment history.

\section{Results}

Thirty-four (47\%) patients scored above the clinical threshold on the AQ (>=26) and 21 (27.8\%) met diagnostic criteria for ASD. These diagnoses had not been made before. Patients with autistic traits showed a borderline significant increase in OCD symptomseverity (Yale-Brown Obsessive Compulsive Scale (Y-BOCS); $\mathrm{p}=.054$ ) and significantly increased impairment of insight (Brown Assessment of Beliefs Scale; $p=.01$ ). There was a positive correlation between AQ and Y-BOCS scores $(\mathrm{p}=.04)$, but not with OCD treatment resistance.

\section{Conclusion}

There is a high prevalence of previously undiagnosed ASD in patients with OCD. ASD traits are associated with greater OCD symptom-severity and poor insight.

\section{Keywords}

Autism spectrum disorders

Obsessive compulsive disorder

Autistic traits

Co-morbidity

Autistic spectrum disorder

Autism 


\section{Main Text}

\section{Introduction}

Obsessive compulsive disorder (OCD) and autism spectrum disorders (ASD) are functionally impairing neuropsychiatric disorders associated with repetitive unwanted, urge-driven behaviours (compulsions) and resulting in considerable morbidity and reduced quality of life. In the case of OCD, the life-time prevalence is 2.3\% (Baldwin et al., 2014) and approximately $40 \%$ of treatment-seeking cases are found to respond poorly (Fineberg et al., 2006). Autism spectrum disorders (ASD), in contrast, affect approximately $1 \%$ of the general population (Elsabbagh et al., 2012, Fombonne, 2005). ASD (classified as Pervasive Developmental Disorders in DSM IV-TR) is characterised by impaired social reciprocity and social communication, as well as repetitive and stereotyped behaviours. DSM-IV-TR distinguished between various subtypes of ASD. Autistic disorder is the prototypical ASD, diagnosed when a person shows the full array of core autistic features in conjunction with a delay in the development of language. By contrast, Asperger's disorder describes those who have the core features of ASD, but who did not have language delay. Pervasive developmental disorder - not otherwise specified (PDD-NOS) is diagnosed when a person has marked and impairing autistic symptoms without quite meeting full criteria for autistic disorder or Asperger's disorder (Mandy et al., 2011). Many of the compulsive behaviours observed in ASD are difficult to differentiate from those observed in OCD (Goodman et al., 1995).

Compulsions are repetitive, stereotyped acts designed to relieve distress. In the case of OCD, compulsions are usually generated in the context of obsessional thoughts or images and appear designed to neutralize the distress associated with these recurrent mental intrusions. For example, the compulsive urge to hand wash in association with the obsessive fear of contamination. Compulsions in OCD are usually experienced as unwanted, are recognised to be excessive or unreasonable and there is usually some attempt at resistance, although this can be minimal especially in chronic cases.

In contrast, in ASD, although the compulsive behaviours may appear similar to those observed in OCD, they are not usually associated with obsessional thoughts or images. Instead, they appear to fulfil one or more complex functions. They may represent a learnt strategy for managing the distress generated by a broad range of environmental contingencies. They may even be experienced as rewarding or soothing. For example, the need to follow an exact routine to avoid having to face unpredictability in the environment. They may also be used to modulate sensory arousal. For example, lower order sensory behaviours such as spinning. They are usually experienced as acceptable or even desirable.

There is emerging empirical evidence that the repetitive behaviours of people with autism are usually egosyntonic, and often serve a function. For example, insistence on sameness in autism appears to be, in part, a deliberate strategy to manage difficult emotions such as anxiety and anger (Joyce et al., 2017) ; whilst autistic obsessions (i.e., focused interests) are usually enjoyable, drive learning and can underpin the development of a positive identity (Bargiela et al., 2016, Mackay and Parry, 2015).

Some OCD dimensions, as identified by factor analysis (Mataix-Cols et al., 2005), occur commonly in ASD. They include hoarding and symmetry and arranging compulsions (Bejerot, 2007, Goodman et al., 1995, Russell et al., 2005). Some individuals with ASD may 
be able to exert control over their compulsions if or when they become aware that they are not socially acceptable (Bejerot, 2007). However, the differences between the compulsions of OCD and ASD are not always that clear-cut and there appears to be a considerable degree of phenotypic overlap. Therefore, in the clinical setting such as an outpatient clinic, distinctions between the compulsions of OCD and ASD can be difficult to make.

OCD and ASD are commonly found to co-occur either in the same patient or in the same family. In a seminal epidemiological study, OCD was found to be common among unaffected (by ASD) relatives of ASD sufferers (Micali et al., 2004). Conversely, a study published by Bejerot and colleagues (Bejerot et al., 2001) using the Asperger's Syndrome diagnostic interview (ASDI), found autistic traits to be common, affecting $13(20 \%)$ of a sample of 64 treatment-seeking patients with OCD. Additionally subjects with autistic traits were more likely to fulfil criteria for anxious and paranoid personality disorder. The authors proposed that OCD is often related to high functioning ASD. Another study (Cullen et al., 2008) investigated the link between social communication difficulties (but not full ASD) in an OCD population that included family members. The study found a higher prevalence of OCD in those families where the proband had both OCD and social communication difficulties, suggesting a possible genetic link between social communication difficulties and OCD. Another more recent large-scale study by Meier and colleagues (Meier et al., 2015) found that individuals diagnosed with OCD displayed a four-fold risk of a co-morbid diagnosis of ASD, and that a diagnosis of ASD lent a two-fold risk of developing co-morbid OCD. The authors also found that a parental diagnosis of OCD significantly increased the risk of the development of ASD in their offspring. The authors concluded that OCD and ASD partially shared aetiological mechanisms, with implications for new research and clinical practice.

Some studies have investigated the impact of autistic traits on the clinical presentation of OCD. In a study of 81 Japanese adult inpatients with OCD (Mito et al., 2014), of whom 34\% scored above threshold on a screening instrument for autistic traits (Autism-Spectrum Quotient, AQ), 50\% met DSM-IV-TR (Association, 2000) criteria for a diagnosis of pervasive developmental disorder. There were no significant differences in age, gender, duration of OCD at baseline or comorbidity with Axis I disorders between the OCD patients with and without autistic traits. However, the analysis did reveal that the group with significant autistic traits included a higher proportion of individuals with poor insight OCD, had a shorter duration of education, lower mean Global Assessment of Functioning Scale scores, earlier age of onset of OCD and were less likely to be married. Another significant finding was that a positive correlation was observed between Yale Brown Obsessive Compulsive scale (YBOCS) scores, representing OCD severity, and the "attention to detail", "attention switching" and "imagination" subscales of the AQ. This suggests that these specific ASD domains may have a moderating effect on OCD severity. In contrast, Ivarrson and colleagues (Ivarsson and Melin, 2008), who investigated children and adolescents with OCD recruited from a Swedish hospital population, found that just roughly 9\% showed symptoms of ASD. The study used a neuro psychiatric assessment supplemented by autism screening questionnaire covering current and preschool autistic symptoms completed by the parents. The study also excluded participants with a primary diagnosis of autism, however Asperger's syndrome was allowed. Interestingly, this study found no correlation between ASD severity, OCD severity, or insight into compulsive behaviours. 
These preliminary findings suggest that further investigation is needed to understand the phenomenology and factors relevant to the aetiology, assessment, diagnosis and treatment of OCD with co-morbid ASD, as this overlap appears likely to impact on clinical outcomes.

\begin{abstract}
Aims
The main aims of the study were to describe the distribution of ASD traits and to identify the proportion of OCD patients with a clinical estimate diagnosis of ASD in a treatment seeking UK OCD population. Secondary aims were to identify any meaningful differences in the demographic and clinical characteristics, of relevance to these diagnoses, associated with this overlap, including gender, partnership status, age of onset of OCD, age at diagnosis of OCD, presence of hoarding and symmetry compulsions, and degree of insight into OCD. The final aim of the study was to investigate whether OCD patients with autistic traits were more treatment-resistant in terms of previous treatments received for their OCD.
\end{abstract}

\title{
Hypotheses
}

At a UK, adulthood OCD outpatient clinic, individuals with clinically significant ASD Traits (including those fulfilling ASD criteria) occur at a higher frequency than in the general population.

Patients with clinically significant ASD traits and patients with ASD diagnosis attending an adult OCD outpatient clinic are distinguishable from OCD patients without ASD or clinically significant ASD traits in terms of:

a. Gender (higher proportion male)

b. Relationship/marital status (greater proportion single/divorced)

c. Age of onset (higher proportion early onset of OCD)

d. Age of diagnosis of OCD (higher proportion diagnosed early)

e. Severity of OCD symptoms (greater total Y-BOCS)

f. Degree of insight in to symptoms of OCD (reduced)

g. Presence of hoarding and symmetry symptoms (more common)

Methodology

The study was approved by the East of England NHS Research Ethics Committee.

\section{Participants}

106 consecutive treatment-seeking adult patients were approached at a specialist OCD clinic from March 2013 to September 2014. They all fulfilled DSM- IV-TR (Association, 2000) criteria for a diagnosis of OCD based on an in-depth clinical assessment by expert clinicians. All patients attending the clinic over this period were offered the opportunity to consent to the study. 


\section{Instruments}

Patients were offered screening on the following instruments;

\section{Autism-Spectrum Quotient}

The Autism-Spectrum Quotient (AQ), developed by Baron Cohen and colleagues (2001), is a 50-item self-reported screening questionnaire that measures autistic traits in adults with normal intelligence. The questionnaire is divided into five domains; communication, imagination, social skills, attention-switching and attention to detail. Each domain is represented by 10 categorical statements (see Table 1 for an example). According to a previous large study (Baron-Cohen et al., 2001), the distribution of total AQ scores in the general population shows a uni-modal distribution, with scores in the range 16-20/50 occurring with the highest frequency. In contrast, high functioning adult ASD patients with normal IQ showed a bi-modal distribution of AQ scores with scores in the range 36-40/50 occurring most commonly. AQ validation studies have demonstrated that, in clinical practice, by using a cut-off score of 26 on the total AQ, it was possible to correctly identify $83 \%$ of all the patients who fulfilled criteria for a DSM IV diagnosis of ASD, with a specificity of 0.52 and sensitivity of 0.95 (Woodbury-Smith et al., 2005).

[Table 1 here]

\section{Yale Brown Obsessive Compulsive Scale (Y-BOCS) and Checklist.}

The Y-BOCS checklist (Goodman et al., 1989b, Goodman et al., 1989a, Woody et al., 1995) is used to evaluate the type of OCD symptoms present or past. It is completed by the clinician in a semi-structured interview. It is divided into various domains relating to common obsessions and compulsions. The checklist leads on to the Y-BOCS itself, which is a validated, 10-item questionnaire rated by the clinician. Items measure the severity of OCD symptoms. The first 5 questions measure obsessions and the remaining 5 measure compulsions. Each item is rated from 0 (no symptoms) to 4 (extreme symptoms). The maximum total score is 40 .

Brown Assessment of Beliefs Scale (BABS).

This clinician-rated scale measures a patient's insight about their beliefs. It consists of seven dimensions; conviction, perception of others' views of beliefs, explanation of differing views, fixity of ideas, attempts to disprove ideas, insight and ideas or delusions of reference. All the dimensions are scored on a four point Likert scale ranging from 0-4 (Eisen et al., 1998).

\section{Clinical Estimate Autism Spectrum Disorders Diagnostic Assessment.}

'Clinical estimate' ASD diagnosis was derived from a clinical interview, structured according to DSM-IV-TR criteria for autism spectrum disorders diagnoses (i.e., autism, Asperger's syndrome, atypical autism), conducted by an experienced psychiatrist. These interviews lasted between 30 and 45 minutes each, and involved systematic questioning relating to each of the core, diagnostic symptoms of ASD, as set out in the DSM-IV-TR. Clinicians were provided with prompts and example questions, to help inform their investigations of each part of the ASD phenotype. For example, when investigating the 
presence of sensory abnormalities, recommended questions included 'Do they have concerns about strong food textures?' and 'Have they ever cut the labels out of clothes or avoided certain fabrics because of sensitivity?' Both current and past behaviour were covered, and decisions on whether a particular symptom was present were made on the basis of both the reports of the participant and observations made by the clinician during the interview. The interview was recorded on an audio tape and assessed by a panel of expert clinicians. A clinical estimate diagnosis was reached based on a predetermined consensus principle.

Intra-class correlation coefficients were calculated for agreement between the four raters on overall diagnosis and for each of the three types of symptoms; Diagnosis: 90 [95\% CI .78, .95], Social reciprocity symptoms: .93 [.85, .97], Communication: .92 [.82, .96], Repetitive behaviour: $83[.65, .92]$. These correlations suggest a strong degree of inter-rater reliability.

\section{Procedure}

Patients were approached and tested at extended clinic appointments by a researcher. All those consenting to participate provided information for a demographic questionnaire and completed the AQ. Participants who scored $26 / 50$ or above were allocated to the (OCD + autistic traits) (OCD+AT) subgroup and were invited to participate in the autism assessment interview described above.

Patients were additionally rated by an experienced psychiatrist for OCD severity using the YBOCS, and for degree of insight using the BABS.

\section{Treatment resistance}

We used the patients' treatment histories to ascertain the degree of treatment resistance. We staged the patients according to prior usage of pharmacological treatment and psychological therapies (table 2). The staging tool was designed by the investigators to capture treatment response data for the purpose of the study, consistent with current evidence-based treatment algorithms for OCD (Stein et al., 2015). We simplified the analysis by dividing the total OCD group into those who had and had not been selected by their treating clinicians to join a highly specialised service for highly resistant OCD cases that defined entry by failure to respond to at least 2 courses of standard SSRI plus one course of pharmacological augmentation as well as two courses of cognitive behaviour therapy for OCD.

[Table 2 here]

\section{Data Analysis}

The data were analysed with IBM SPSS Statistic 21 . When comparing groups on continuous dependent variables, independent samples t-tests were used. Chi squared analysis was performed to compare groups on categorical variables. Effect sizes were presented as Cohen's d (continuous variables) or odds ratios (categorical variables). 


\section{Results}

\section{Diagnosis}

$73(69 \%)$ of the eligible patients consented to take part. The mean age of the group was 44.47 years. There was a positive significant correlation between the total Y-BOCS and the total AQ scores $(p=.04)$. Thirty-four patients $(47 \%)$ scored 26 or above on the AQ (OCD+AT). Of these, 29 were interviewed using the Clinical Estimate Autism Spectrum Disorders Diagnostic Assessment and 21 (62\% of the OCD+AT group; $28.7 \%$ of the study sample) were given an estimate diagnosis of autism spectrum disorders (OCD+ASD) (see fig.1), of whom 12 fulfilled criteria for Asperger's syndrome, 7 for PDD NOS and 2 for autism, based on DSM-IV criteria.

[Figure 1 here]

\section{Descriptive Statistics}

\section{Gender and Partnership Status}

There was a slight preponderance of females (53.4\%) in the total group and approximately two thirds of all cases were living alone, with $57.5 \%$ never having been married or lived in a stable partnership. A Chi squared test for independence (with Yates Continuity Correction) indicated that there was no significant association between the presence of autistic traits and gender $\left(\mathrm{OCD}+\mathrm{AT}\right.$ versus OCD-AT); $\left.X^{2}(1, \mathrm{n}=73)=.61, p=.43\right)$; or partnership status $(\mathrm{OCD}+\mathrm{AT}$ versus OCD-AT $) ; X^{2}(2, \mathrm{n}=73)=0.48, p=0.79$, in the OCD sample. Similarly, there was no significant association between the presence of an ASD diagnosis and gender $\left(\mathrm{OCD}+\mathrm{ASD}\right.$ versus OCD-AT) $X^{2}(1, \mathrm{n}=60)=.33, p=.57$ or partnership status (OCD+AT versus $\mathrm{OCD}-\mathrm{AT}) ; X^{2}(2, \mathrm{n}=60)=1.36, p=.51$.

\section{OCD Onset, Diagnosis, Severity and Degree of Insight and Autistic Traits}

[Table 3 here]

The average age of onset of OCD across the whole sample was 14.58 ( $\mathrm{SD}=8.53)$ years. In contrast, the mean age at diagnosis of OCD in the whole sample was $28.51(\mathrm{SD}=11.8)$ years, suggesting an average lag between onset and diagnosis of around 14 years. As can be seen in Table 3, those scoring above and below the AQ's clinical threshold of 26 did not differ in their current age, reported age of onset of OCD, or in the age at which they received an OCD diagnosis. Table 3 shows that on the Y-BOCS 'Compulsions' and 'Obsessions' scales there were no differences between those above and below the AQ threshold. However, there was a non-significant trend $(\mathrm{p}<.054)$ towards those scoring with high ATs also showing increased overall OCD symptom severity, as measured by the Y-BOCS total score. Table 4 shows a comparison between AQ-defined groups for individual symptoms of OCD, as measured by the Y-BOCS. There was evidence that the OCD+AT group had less insight into their OCD symptoms than those without high ATs, as shown by the group difference on the BABS, which was large and significant (effect size $=-.65[-1.13,-.15], \mathrm{p}=.01$ ).

[Table 4 here] 
As is shown in Table 5, we also looked at those with an estimate ASD diagnosis, excluding those who scored above the clinical range on the AQ but were not subsequently identified as having ASD, and compared them to participants who had OCD, but no ASD diagnosis. No group differences were found in terms of current age, OCD age of onset, OCD age of diagnosis, insight or severity, as indexed by the Y-BOCS 'Compulsions', 'Obsessions' and total scores.

[Table 5 here]

\section{Treatment resistance}

The majority of patients across the whole sample (52/73 (71\%)) had failed at least one evidence based treatment. However there was no significant difference between those with and without autistic traits in terms of treatment stage (OCD+AT versus OCD-AT; $p=.31$ ). Similarly, there was no significant difference between those with and without ASD and treatment stage (OCD+ASD vs OCD-AT; $p=.43)$.

Twenty-four (33\%) patients were receiving treatment in the highly resistant OCD service. Owing to abnormal variance we applied the Yates Continuity Correction, which indicated that there was no significant association between the proportion of patients requiring treatment resistant OCD services and the presence of autistic traits (OCD+AT vs OCD-AT; $p$ $=.56)$ or the presence of ASD (OCD+ASD vs OCD-AT $p=.29)$.

\section{Distribution of $A Q$ scores}

[Figure 2 here]

In our total OCD sample, the distribution of total AQ scores, representing the number of ASD traits, was found to lie mid-way between that of the general population and that of the ASD comparator groups (from the previously published study by Baron Cohen et al., 2001) with scores in the range 21-25/50 $(M=24.74, S D=8.17)$ being endorsed most frequently (figure 2$)$. The OCD sub-groups with defined autistic traits $(\mathrm{OCD}+\mathrm{AT})$ and an estimate diagnosis of ASD (OCD+ASD) each endorsed AQ scores between 26-30/50. Thus, the OCD patients with co-morbid estimate diagnosis of ASD were not seemingly scoring in general as high on the AQ as did a formally diagnosed ASD sample. This finding may reflect possible ascertainment bias in that the majority of OCD patients had not been given a clinical ASD diagnosis and may thus be inferred to represent a more mildly autistic group.

\section{Profile of AQ domains affected in OCD patients with autistic traits}

The OCD+AT group scored high in all AQ domains, most especially in the domain of attention switching (mean 8.45 out of 10 items endorsed) in which domain they were numerically more impaired than were the previously published ASD group (figure 3 ). The OCD group without autistic traits (OCD-AT) were also numerically more impaired than the normal population comparator group on the same domain, suggesting the presence of a moderating effect of OCD on this domain. Importantly, we also found that the OCD $+A T$ group showed poor social skills. 
[Figure 3 here]

\section{Discussion}

OCD includes a heterogeneous group of patients without a clear consensus on how to subdivide the disorder into clinically meaningful subtypes (Lochner and Stein, 2003). According to DSM-IV and DSM-5 (American Psychiatric Association. and American Psychiatric Association. DSM-5 Task Force., 2013) the level of insight and the presence of tic represent specifiers that may determine clinical outcomes. It has been proposed that OCD patients with comorbid ASD may represent yet another clinically relevant 'neurodevelopmental' OCD subtype, associated with a poor response to standard treatment (Bejerot, 2007, Russell et al., 2013, Koegel and Koegel, 1998). Alternatively, ASD compulsions may be mis-diagnosed as $\mathrm{OCD}$, and this may explain why these patients might fail to respond to standard OCD treatments. In a recent brain-imaging study, Kobayashi and colleagues (KOBAYASHI et al., 2015) found that reductions in the volume of the left dorsolateral prefrontal cortex and amygdala correlated positively with AQ scores. The authors suggested that these changes define a biologically distinct OCD subgroup, with implications for the development of more appropriate therapy and treatment.

In our study, we explored the co-occurrence of ASD traits and diagnosis on the clinical presentation and treatment outcomes of a moderately-sized sample of treatment-seeking OCD patients, in an attempt to better understand this inter-relationship and draw inferences on the role of ASD in defining a specific OCD subgroup. We found a high prevalence of ASD traits (47\%) and diagnosis $(29 \%)$ in the OCD sample. Not one of these patients had previously been recognized as having ASD traits, despite in many case multiple clinic visits, emphasising the difficulty of recognizing ASD within this clinical group and implying that active screening for ASD in OCD patients may be helpful.

The level of ASD traits found in our study exceeded those reported by Mito and colleagues (2014) in a Japanese sample of adults with OCD, in which $34 \%$ and $17 \%$ showed ASD traits and diagnosis respectively and Bejerot and colleagues (2001), who found $20 \%$ of a child and adolescent cohort of OCD patients with ASD. One explanation for the higher frequency of autistic traits in our study may derive from the use of a lower threshold for defining this group. Unlike Mito et al (2010) who chose an AQ score of 32, we used a cutoff of 26, as per the work of Woodbury-Smith et al (2005). Judging by the distribution of the AQ scores in our OCD+AT group, which did not appear to differ from the distribution of AQ scores of those given a clinical estimate diagnosis of ASD, we believe the cut off we used was valid and that our findings do not over-estimate clinically relevant autistic traits in our sample. Moreover, we believe our frequency data may represent a conservative estimate of the frequency of autistic traits in the whole clinic sample, as it was our observation that a substantial proportion of those refusing to consent to screening for ASD $(\mathrm{N}=33)$ may have had autistic traits as well, though we were unable to validate this observation for ethical reasons.

Taken together with the existing published data, our findings indicate that the prevalence of ASD is elevated in treatment seeking OCD patients, perhaps by at least twenty times that of the normal population and that we may expect roughly half of adults seeking treatment for OCD to demonstrate clinically relevant comorbid ASD traits. 
The autistic traits that were the most strongly endorsed involved problems with flexibly shifting attention, on which ASD domain the OCD sample appeared numerically even more impaired than the a published ASD cohort (see figure 3). Attentional set-shifting problems are observed on cognitive testing in OCD (Fineberg et al., 2013) and similar abnormalities are also seen in ASD (Gioia et al., 2002), suggesting that an area of neurocognitive overlap manifesting as cognitive inflexibility exists across these two separate disorders that may account for these findings. However, other autistic traits not inherently associated with OCD were also frequently endorsed by the OCD patients in this study, including poor social, communication and imaginative skills, providing support for a true diagnostic overlap with ASD. Further studies examining the neurocognitive underpinnings of these changes may help to clarify the extent to which the same or different neurocognitive mechanisms (and possibly neural mechanisms) occur across patients with OCD, ASD and the combination of both disorders. The nature of these clinical changes suggests that collaboration between clinicians and academics with expertise in neurodevelopmental as well as psychiatric disorders may benefit the research and treatment of this significant patient group.

In our sample, the OCD patients with autistic traits and with ASD showed a similar demographic profile in terms of gender distribution, employment and marital status as those without autistic traits. The failure to find a preponderence of males in these groups is consistent with other published studies (Bejerot et al., 2001, Mito et al., 2014). ASD is reported to be more commonly misdiagnosed in females than males and symptomatic females with undiagnosed ASD may as a result show over-represention in other non-ASD psychiatric clinics and services (Bargiela et al., 2016). Therefore, the relative over-representation of females with autistic traits in our OCD service may result from ascertainment bias related to the general failure to recognize ASD in females and suggests that clinicians should be particularly careful to look for ASD in female patients presenting for treatment of OCD.

In contrast to the study by Mito et al (Mito et al., 2014), the age of onset of OCD and age of diagnosis of OCD did not differ between the groups. Indeed the mean age of onset of OCD occurred around adolescence (14-15yrs).This was contrary to expectation, as we had hypothesized that the presence of an early onset neuro-developmental disorder would have led to an earlier onset or diagnosis of OCD. Our findings suggest that the presence of autistic traits or of ASD may not affect the natural course of OCD. However, this data was collected retrospectively and patients' recall may have been unreliable. Moreover, there was a considerable delay of approximately 14 years between the reported onset of illness and diagnosis irrespective of the presence of autistic traits or ASD, suggesting that a ceiling effect could have obscured a true moderating effect of ASD on age of illness onset. Our finding provides further sobering evidence that OCD is a poorly recognized illness (Dell'Osso et al., 2010) with a long duration of untreated disorder. It also suggests that future research should explore the onset and course of OCD and ASD prospectively, in longitudinal cohorts of children and adolescents.

OCD patients with autistic traits were more severely symptomatic on the Y-BOCS and there was a positive correlation between OCD and ASD scores. This finding replicates that of Mito et al (2014). It is commonly found that co-morbid disorders predict a greater severity of index illness (Fineberg et al., 2013) and this finding may therefore simply represent a non-specific effect reflecting the burden of having an additional mental health diagnosis. However, it was noteworthy that a high frequency of traits in a range of ASD domains (attention switching, social skills) was found in this co-morbid group. In other words, the presence co-morbid ASD 
brought with it an additional clinical burden related to the ASD traits themselves. The clinical impact of these additional problems e.g. on health related quality of life, merits further investigation. Based on our data, there would be grounds for investigating new treatment strategies, e.g. focussing on cognitive remediation, to improve cognitive flexibility and social skills training.

The correlations between poor insight and autistic traits were also significant. Theoretically, poor insight should impact negatively on OCD treatment outcome (Himle et al., 2006). However, contrary to expectation, despite increased symptom-severity and poorer insight, the OCD +AT group did not appear to be more treatment refractory on the measures we used (past treatment history, service stream). This may also represent a ceiling effect, in as much as all the OCD patients had been ill for a very long time and there was a high proportion of treatment-resistant cases among them. In addition, the retrospective nature of the methods used to infer treatment resistance was open to error.

Considering the study findings of high prevalence rates of AT/ASD, the non-significant trend toward a positive correlation between AQ and Y-BOCS scores, and the negative results of most comparisons between the study groups, the possibility of phenomenological overlap between some autistic traits (as measured by the AQ) and OCD symptoms or clinical features needs to be acknowledged. It is possible that the AQ may have been measuring behaviours that are also frequent among OCD sufferers without autistic traits. Therefore, instead of under-identification, the possibility of over-identification of ASD or ASD traits (i.e. falsepositive cases) such that OCD compulsions/avoidant behaviours may have been misinterpreted as autistic traits, should be considered. However, the finding of significantly poorer insight in the OCD + AT group provides some evidence that a high AQ score may indeed reflect a separate process illness. Furthermore, the finding that 21 out of 34 patients scoring above 25 on the AQ were, following a detailed clinical assessment, judged to fulfil DSM-IV ASD criteria, provides stronger evidence supporting ASD comorbidity in a majority of these patients.

\section{Limitations}

We must acknowledge the possibility of false-positives due to the low specificity of the AQ and the issue of clinical overlap of observed behaviours. In addition, although the BABS is the established scale for measuring insight in OCD, the score may be influenced by OCD symptoms content and cannot be totally relied upon (Brakoulias and Starcevic, 2011). The non-significant trend in total Y-BOCS score in the OCD + AT group may have resulted from a type 2 error. Other psychiatric comorbidities were not investigated and could also have had an impact on several explanatory variables (e.g. partnership status, level of insight), as well as on treatment outcome. The fact that the participants were treated at a specialized OCD clinic may limit the external validity of the study.

\section{Conclusions}

The high prevalence of previously undiagnosed ASD in both male and female outpatients with treatment seeking OCD, and the associated impairment on scales measuring insight, cognitive flexibility and social communication skills, indicates a clinically relevant neurodevelopmental OCD subgroup that merits further multidisciplinary investigation to improve recognition and develop new and more effective clinical treatments and services to optimize outcomes. 


\section{Key Points}

- $\quad$ ASD traits were found to commonly occur in OCD outpatients

- In the main, the presence of comorbid ASD traits had been previously overlooked by clinicians.

- $\quad$ OCD patients with high levels of ASD traits showed greater impairment of insight, social skills, social communication and cognitive flexibility.

\section{Acknowledgements}

We would like to acknowledge the contribution of the patients and the administrative staff in the Highly Specialized Obsessive Compulsive Disorders Service, Hertfordshire Partnership University NHS Foundation Trust. Special thanks to Dr Keith O'Sullivan and Dr David Wellsted at the University of Hertfordshire for their help with the analysis and Mr Lasantha Wikramanayake for his contribution to the graphics.

\section{Disclosure of interest}

In the past several years, Dr. Fineberg has received research support from Lundbeck, GlaxoSmithKline, European College of Neuropsychopharmacology (ECNP), Servier, Cephalon, Astra Zeneca, Medical Research Council (UK), National Institute for Health Research, Wellcome Foundation, University of Hertfordshire, EU (FP7), Shire. Dr Fineberg has received honoraria for lectures at scientific meetings from Otsuka, Lundbeck, Servier, Astra Zeneca, Jazz pharmaceuticals, Bristol Myers Squibb, UK College of Mental Health Pharmacists, British Association for Psychopharmacology (BAP). Dr Fineberg has received financial support to attend scientific meetings from RANZCP, Shire, Janssen, Lundbeck, Servier, Novartis, Bristol Myers Squibb, Cephalon, International College of ObsessiveCompulsive Spectrum Disorders, International Society for Behavioural Addiction, CINP, IFMAD, ECNP, BAP, World Health Organization, Royal College of Psychiatrists. Dr Fineberg has received financial royalties for publications from Oxford University Press and payment for editorial duties from Taylor and Francis. 


\section{References}

AMERICAN PSYCHIATRIC ASSOCIATION. \& AMERICAN PSYCHIATRIC ASSOCIATION. DSM-5 TASK FORCE. 2013. Diagnostic and statistical manual of mental disorders : DSM-5, Washington, D.C., American Psychiatric Association.

ASSOCIATION, A. P. 2000. Diagnostic and statistical manual of mental disorders (DSM-IV-TR), Washington DC, American Psychiatric Association,.

BALDWIN, D. S., ANDERSON, I. M., NUTT, D. J., ALLGULANDER, C., BANDELOW, B., DEN BOER, J. A., CHRISTMAS, D. M., DAVIES, S., FINEBERG, N. \& LIDBETTER, N. 2014. Evidence-based pharmacological treatment of anxiety disorders, post-traumatic stress disorder and obsessivecompulsive disorder: a revision of the 2005 guidelines from the British Association for Psychopharmacology. Journal of Psychopharmacology, 28, 403-439.

BARGIELA, S., STEWARD, R. \& MANDY, W. 2016. The Experiences of Latediagnosed Women with Autism Spectrum Conditions: An Investigation of the Female Autism Phenotype. Journal of Autism and Developmental Disorders, 46, 3281-3294.

BARON-COHEN, S., WHEELWRIGHT, S., SKINNER, R., MARTIN, J. \& CLUBLEY, E. 2001. The autism-spectrum quotient (AQ): Evidence from asperger syndrome/high-functioning autism, malesand females, scientists and mathematicians. Journal of autism and developmental disorders, 31, 5-17.

BEJEROT, S. 2007. An autistic dimension A proposed subtype of obsessivecompulsive disorder. Autism, 11, 101-110.

BEJEROT, S., NYLANDER, L. \& LINDSTRÖM, E. 2001. Autistic traits in obsessivecompulsive disorder. Nordic Journal of Psychiatry, 55, 169-176.

BRAKOULIAS, V. \& STARCEVIC, V. 2011. The characterization of beliefs in obsessive-compulsive disorder. Psychiatric Quarterly, 82, 151-161.

CULLEN, B., SAMUELS, J., GRADOS, M., LANDA, R., BIENVENU, O. J., LIANG, K.-Y., RIDDLE, M., HOEHN-SARIC, R. \& NESTADT, G. 2008. Social and communication difficulties and obsessive-compulsive disorder. Psychopathology, 41, 194-200.

DELL'OSSO, B., BUOLI, M., HOLLANDER, E. \& ALTAMURA, A. 2010. Duration of untreated illness as a predictor of treatment response and remission in obsessive-compulsive disorder. The world journal of biological psychiatry, 11, 59-65.

EISEN, J. L., PHILLIPS, K. A., BAER, L., BEER, D. A., ATALA, K. D. \& RASMUSSEN, S. A. 1998. The brown assessment of beliefs scale: reliability and validity. American Journal of Psychiatry, 155, 102-108.

ELSABBAGH, M., DIVAN, G., KOH, Y. J., KIM, Y. S., KAUCHALI, S., MARCIN, C., MONTIEL-NAVA, C., PATEL, V., PAULA, C. S., WANG, C., YASAMY, M. T. \& FOMBONNE, E. 2012. Global prevalence of autism and other pervasive developmental disorders. Autism Res, 5, 160-79.

FINEBERG, N., GALE, T. M. \& SIVAKUMARAN, T. 2006. A review of antipsychotics in the treatment of obsessive compulsive disorder. Journal of Psychopharmacology.

FINEBERG, N. A., HENGARTNER, M. P., BERGBAUM, C. E., GALE, T. M., GAMMA, A., AJDACIC-GROSS, V., RÖSSLER, W. \& ANGST, J. 2013. A prospective population-based cohort study of the prevalence, incidence and 
impact of obsessive-compulsive symptomatology. International journal of psychiatry in clinical practice, 17, 170-178.

FOMBONNE, E. 2005. The Changing Epidemiology of Autism. Journal of Applied Research in Intellectual Disabilities, 18, 281-294.

GIOIA, G. A., ISQUITH, P. K., KENWORTHY, L. \& BARTON, R. M. 2002. Profiles of everyday executive function in acquired and developmental disorders. Child neuropsychology, 8, 121-137.

GOODMAN, W. K., NAYLOR, S. T. \& VOLKMAR, F. R. 1995. A case-controlled study of repetitive thoughts and behavior in adults with autistic disorder and obsessive-compulsive disorder. The American journal of psychiatry, 152, 5.

GOODMAN, W. K., PRICE, L. H., RASMUSSEN, S. A., MAZURE, C., DELGADO, P., HENINGER, G. R. \& CHARNEY, D. S. 1989a. The yale-brown obsessive compulsive scale: II. Validity. Archives of general psychiatry, 46, 1012-1016.

GOODMAN, W. K., PRICE, L. H., RASMUSSEN, S. A., MAZURE, C., FLEISCHMANN, R. L., HILL, C. L., HENINGER, G. R. \& CHARNEY, D. S. 1989b. The Yale-Brown obsessive compulsive scale: I. Development, use, and reliability. Archives of general psychiatry, 46, 1006-1011.

HIMLE, J. A., VAN ETTEN, M. L., JANECK, A. S. \& FISCHER, D. J. 2006. Insight as a predictor of treatment outcome in behavioral group treatment for obsessivecompulsive disorder. Cognitive Therapy and Research, 30, 661-666.

IVARSSON, T. \& MELIN, K. 2008. Autism spectrum traits in children and adolescents with obsessive-compulsive disorder (OCD). Journal of anxiety disorders, 22, 969-978.

JOYCE, C., HONEY, E., LEEKAM, S. R., BARRETT, S. L. \& RODGERS, J. 2017. Anxiety, Intolerance of Uncertainty and Restricted and Repetitive Behaviour: Insights Directly from Young People with ASD. Journal of Autism and Developmental Disorders, 1-14.

KOBAYASHI, T., HIRANO, Y., NEMOTO, K., SUTOH, C., ISHIKAWA, K., MIYATA, H., MATSUMOTO, J., MATSUMOTO, K., MASUDA, Y. \& NAKAZATO, M. 2015. Correlation between Morphologic Changes and Autism Spectrum Tendency in Obsessive-Compulsive Disorder. Magnetic Resonance in Medical Sciences.

KOEGEL, M. J. B. R. L. \& KOEGEL, L. K. 1998. Increasing the Social Behavior of Young Children With Autism Using Their Obsessive Behaviors.

LOCHNER, C. \& STEIN, D. J. 2003. Heterogeneity of obsessive-compulsive disorder: a literature review. Harvard review of psychiatry, 11, 113-132.

MACKAY, S. J. \& PARRY, O. 2015. Two world views: Perspectives on autistic behaviours. Journal of health psychology, 20, 1416-1426.

MANDY, W., CHARMAN, T., GILMOUR, J. \& SKUSE, D. 2011. Toward specifying pervasive developmental disorder-not otherwise specified. Autism Research, $4,121-131$.

MATAIX-COLS, D., DO ROSARIO-CAMPOS, M. C. \& LECKMAN, J. F. 2005. A multidimensional model of obsessive-compulsive disorder. American Journal of Psychiatry.

MEIER, S. M., PETERSEN, L., SCHENDEL, D. E., MATTHEISEN, M., MORTENSEN, P. B. \& MORS, O. 2015. Obsessive-Compulsive Disorder and Autism Spectrum Disorders: Longitudinal and Offspring Risk. PLoS One, 10, e0141703.

MICALI, N., CHAKRABARTI, S. \& FOMBONNE, E. 2004. The broad autism phenotype findings from an epidemiological survey. Autism, 8, 21-37. 
MITO, H., MATSUURA, N., MUKAI, K., YANAGISAWA, Y., NAKAJIMA, A., MOTOYAMA, M., ARIKAWA, A., YAMANISHI, K. \& MATSUNAGA, H. 2014. The impacts of elevated autism spectrum disorder traits on clinical and psychosocial features and long-term treatment outcome in adult patients with obsessive-compulsive disorder. Comprehensive Psychiatry, 55, 1526-1533.

RUSSELL, A. J., JASSI, A., FULLANA, M. A., MACK, H., JOHNSTON, K., HEYMAN, I., MURPHY, D. G. \& MATAIX - COLS, D. 2013. COGNITIVE BEHAVIOR THERAPY FOR COMORBID OBSESSIVE - COMPULSIVE DISORDER IN HIGH - FUNCTIONING AUTISM SPECTRUM DISORDERS: A

RANDOMIZED CONTROLLED TRIAL. Depression and Anxiety, 30, 697-708.

RUSSELL, A. J., MATAIX-COLS, D., ANSON, M. \& MURPHY, D. G. 2005.

Obsessions and compulsions in Asperger syndrome and high-functioning autism. The British Journal of Psychiatry, 186, 525-528.

STEIN, D. J., FINEBERG, N. \& REGHUNANDANAN, S. 2015. ObsessiveCompulsive and Related Disorders, Oxford University Press, USA.

WOODBURY-SMITH, M. R., ROBINSON, J., WHEELWRIGHT, S. \& BARONCOHEN, S. 2005. Screening adults for Asperger syndrome using the $A Q$ : $A$ preliminary study of its diagnostic validity in clinical practice. Journal of autism and developmental disorders, 35, 331-335.

WOODY, S. R., STEKETEE, G. \& CHAMBLESS, D. L. 1995. Reliability and validity of the Yale-Brown obsessive-compulsive scale. Behaviour research and therapy, 33, 597-605.

\section{Legends of Tables and figures}

Figure 1 legend

OCD N $=73$

- general population $\mathrm{N}=174$

$--\operatorname{ASDN}=58$

Figure 2 legend

$$
\begin{aligned}
& \square \mathrm{OCD}+\mathrm{AT} N=34 \\
& \text { OCD }-\mathrm{AT} N=39 \\
& \text { Controls } \mathrm{N}=174 \\
& \text { ASD N }=58
\end{aligned}
$$




\section{Tables}

Table 1. An example of a statement for each of the AQ domains

\section{Domain Statement}

Social skills I find it hard to make friends.

Attention switching I frequently get so absorbed in one activity that I lose sight of others.

Attention to detail I am fascinated by numbers.

Communication Other people tell me what I have said is impolite even though I think it is polite.

Imagination

When I am reading a story book, I find it difficult to figure out the characters' intentions.

Table 2: Treatment stage

\begin{tabular}{|l|l|}
\hline Stage & Details \\
\hline Stage 1 & Treatment naive \\
\hline Stage 2 & Inadequate course of evidence based treatment \\
\hline Stage 3 & Responded to course of treatment \\
\hline Stage 4 & $\begin{array}{l}\text { Failed one course of CBT or evidence based pharmacological } \\
\text { treatment with good adherence }\end{array}$ \\
\hline Stage 5 & $\begin{array}{l}\text { Failed 2 courses of CBT or 2 courses evidence based pharmacological } \\
\text { treatment with good adherence }\end{array}$ \\
\hline Stage 6 & $\begin{array}{l}\text { Failed } 2 \text { courses of CBT including home based therapy or evidence } \\
\text { based pharmacological therapy augmented with antipsychotic or high } \\
\text { dose SSRI }\end{array}$ \\
\hline Stage 7 & $\begin{array}{l}\text { Failed 2 courses of CBT including inpatient CBT or augmentation of } \\
\text { evidenced based pharmacological therapy with novel compounds }\end{array}$ \\
\hline
\end{tabular}


Table 3. Comparison of OCD characteristics of those scoring above and below Autism Spectrum Quotient threshold

\begin{tabular}{|l|c|c|c|c|}
\hline & $\mathrm{AQ} \geq 26$ & $\mathrm{AQ}<26$ & Effect size & $\mathrm{P}$ \\
\hline & $\mathrm{n}=34$ & $\mathrm{n}=39$ & & \\
& Mean $(\mathrm{SD})$ & Mean $(\mathrm{SD})$ & $\begin{array}{c}\text { Cohen's d } \\
{[95 \% \text { CIs }]}\end{array}$ & \\
\hline Age at time of current study in & 45.18 & 43.85 & -.11 & .644 \\
years & $(12.16)$ & $(12.25)$ & {$[-.57, .35]$} & \\
\hline Age at OCD onset in years & 15.11 & 14.10 & -.11 & .993 \\
& $(9.17)$ & $(1.29)$ & {$[-.58, .34]$} & \\
\hline Age at OCD diagnosis in years & 29.21 & 29.18 & .00 & .606 \\
& $(13.80)$ & $(10.10)$ & {$[-.46, .46]$} & \\
\hline Age started OCD treatment in & 30.29 & 29.90 & -.03 & .891 \\
years & $(13.85)$ & $(10.68)$ & {$[-.49, .43]$} & \\
\hline YBOCS OCD symptoms & & & & \\
\hline Compulsions & 11.60 & 9.84 & -.41 & .104 \\
& $(3.97)$ & $(4.52)$ & {$[-.90, .08]$} & \\
\hline Obsessions & 10.28 & 9.21 & -.25 & .310 \\
& $(4.41)$ & $(4.07)$ & {$[-.74, .24]$} & \\
\hline Total & 21.82 & 18.05 & -.49 & .054 \\
& $(7.43)$ & $(7.93)$ & {$[-.98, .01]$} & \\
\hline BABS Total & 8.10 & 4.84 & -.65 & .011 \\
& $(5.78)$ & $(4.42)$ & {$[-1.13,-.15]$} & \\
\hline
\end{tabular}


Table 4 Y-BOCS symptom checklist items for those scoring above and below threshold on the Autism Quotient

\begin{tabular}{|c|c|c|c|c|}
\hline & $\mathrm{AQ} \geq 26$ & $\mathrm{AQ}<26$ & $\begin{array}{l}\text { Odds ratio } \\
{[95 \% \mathrm{CI}]}\end{array}$ & $\mathrm{P}$ \\
\hline & $\mathrm{n}=30$ & $\mathrm{n}=39$ & & \\
\hline & $\begin{array}{c}\mathrm{n} \text { with } \\
\text { symptom }(\%)\end{array}$ & $\mathrm{n}(\%)$ & & \\
\hline \multicolumn{5}{|l|}{ Obsessions } \\
\hline Aggressive & $19(65.5 \%)$ & $22(56.4 \%)$ & $\begin{array}{l}1.47 \\
{[.49,4.49]}\end{array}$ & .448 \\
\hline Contamination $^{1}$ & $18(62.1 \%)$ & $27(69.2 \%)$ & $\begin{array}{l}.72 \\
{[.23,2.26]}\end{array}$ & .537 \\
\hline Sexual $^{1}$ & $7(24.1 \%)$ & $6(15.4 \%)$ & $\begin{array}{l}1.75 \\
{[.43,7.18]}\end{array}$ & .364 \\
\hline Hoarding $^{1}$ & $12(41.4 \%)$ & $14(35.9)$ & $\begin{array}{l}1.26 \\
{[.42,3.78]}\end{array}$ & .645 \\
\hline Religious $^{\mathrm{I}}$ & $7(24.2 \%)$ & $8(20.5 \%)$ & $\begin{array}{l}1.23 \\
{[.33,4.54]}\end{array}$ & \\
\hline Symmetry $^{2}$ & $11(36.7 \%)$ & $15(38.5 \%)$ & $\begin{array}{l}.93 \\
{[.31,2.76]}\end{array}$ & \\
\hline Miscellaneous ${ }^{2}$ & $18(60.0 \%)$ & $22(57.9 \%)$ & $\begin{array}{l}1.09 \\
{[.37,3.24]}\end{array}$ & .860 \\
\hline \multicolumn{5}{|l|}{ Compulsions } \\
\hline Somatic & $8(26.7 \%)$ & $18(46.15)$ & & .098 \\
\hline Cleanliness & $19(63.3 \%)$ & $26(66.7 \%)$ & .86 & .773 \\
\hline Checking & $21(70.0 \%)$ & $28(71.8 \%)$ & $\begin{array}{l}.92 \\
{[.28,3.01]}\end{array}$ & .871 \\
\hline Repeating & $19(63.3 \%)$ & $22(56.4 \%)$ & $\begin{array}{l}1.33 \\
{[.45,3.99]}\end{array}$ & .562 \\
\hline Counting & $16(53.3 \%)$ & $17(43.6 \%)$ & $\begin{array}{l}1.48 \\
{[.51,4.29]}\end{array}$ & .422 \\
\hline Ordering & $11(36.7 \%)$ & $14(35.9 \%)$ & $\begin{array}{l}1.03 \\
{[.34,3.11]}\end{array}$ & .948 \\
\hline Hoarding & $8(26.7 \%)$ & $13(33.3 \%)$ & $\begin{array}{l}.72 \\
{[.22,2.33]}\end{array}$ & .551 \\
\hline Miscellaneous & $23(76.7 \%)$ & $23(59.0 \%)$ & $\begin{array}{l}2.29 \\
{[.71,7.79]}\end{array}$ & .122 \\
\hline
\end{tabular}

${ }^{1} \mathrm{AQ} \geq 26 \mathrm{n}=29$ 
Table 5. Comparison of OCD characteristics of those with and without estimate ASD diagnosis

\begin{tabular}{|c|c|c|c|c|}
\hline & ASD & Non ASD & Effect size & $\mathrm{P}$ \\
\hline & $\mathrm{n}=21$ & $\mathrm{n}=48$ & & \\
\hline & Mean (SD) & Mean (SD) & $\begin{array}{l}\text { Cohen's d } \\
{[95 \% \text { CIs] }}\end{array}$ & \\
\hline $\begin{array}{l}\text { Age at time of current study } \\
\text { in years }\end{array}$ & $\begin{array}{c}45.33 \\
(11.41)\end{array}$ & $\begin{array}{c}44.41 \\
(12.64)\end{array}$ & $\begin{array}{c}-.07 \\
{[-.59, .44]}\end{array}$ & .776 \\
\hline Age at OCD onset in years & $\begin{array}{l}12.38 \\
(5.70)\end{array}$ & $\begin{array}{l}14.94 \\
(9.02)\end{array}$ & $\begin{array}{c}.31 \\
{[-.20, .83]}\end{array}$ & .236 \\
\hline $\begin{array}{l}\text { Age at OCD diagnosis in } \\
\text { years }\end{array}$ & $\begin{array}{c}30.57 \\
(13.58)\end{array}$ & $\begin{array}{c}28.68 \\
(11.45)\end{array}$ & $\begin{array}{c}-.16 \\
{[-.67, .36]}\end{array}$ & .555 \\
\hline $\begin{array}{l}\text { Age started OCD treatment } \\
\text { in years }\end{array}$ & & & & \\
\hline \multicolumn{5}{|l|}{ YBOCS OCD symptoms } \\
\hline Compulsions & $\begin{array}{l}10.67 \\
(3.44) \\
\end{array}$ & $\begin{array}{l}10.33 \\
(4.61) \\
\end{array}$ & $\begin{array}{c}-.08 \\
{[-.62, .47]}\end{array}$ & \\
\hline Obsessions & $\begin{array}{c}9.22 \\
(4.19)\end{array}$ & $\begin{array}{c}9.61 \\
(4.17)\end{array}$ & {$[-.45, .64]$} & .310 \\
\hline Total & $\begin{array}{r}19.89 \\
(6.53) \\
\end{array}$ & $\begin{array}{l}19.07 \\
(8.16)\end{array}$ & {$[-.65, .44]$} & .704 \\
\hline BABS Total & $\begin{array}{c}7.68 \\
(6.05) \\
\end{array}$ & $\begin{array}{c}5.70 \\
(4.99) \\
\end{array}$ & {$[-.91, .17]$} & .175 \\
\hline
\end{tabular}




\section{Figures}

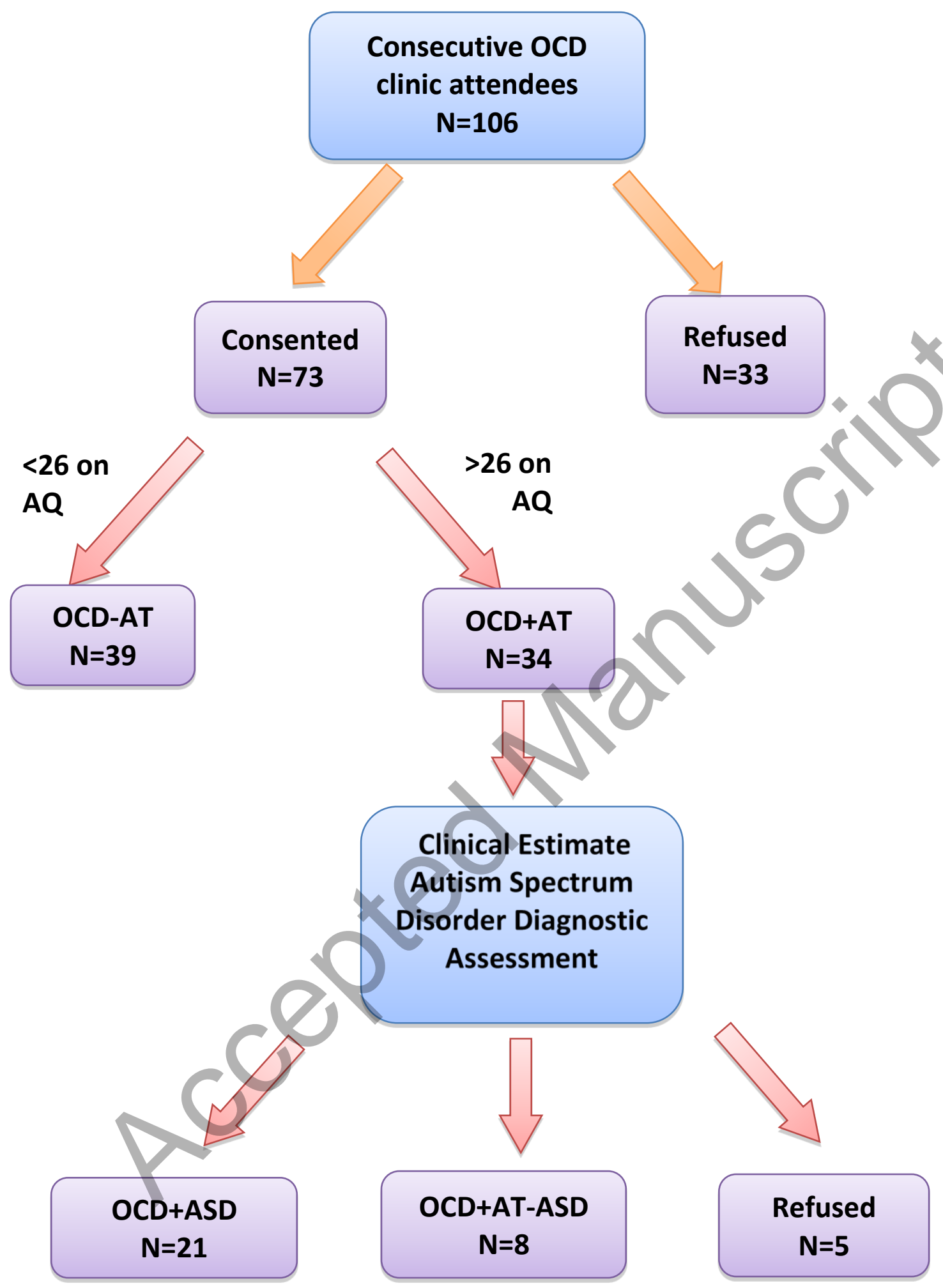

Figure 1. Number of participants recruited into each group 


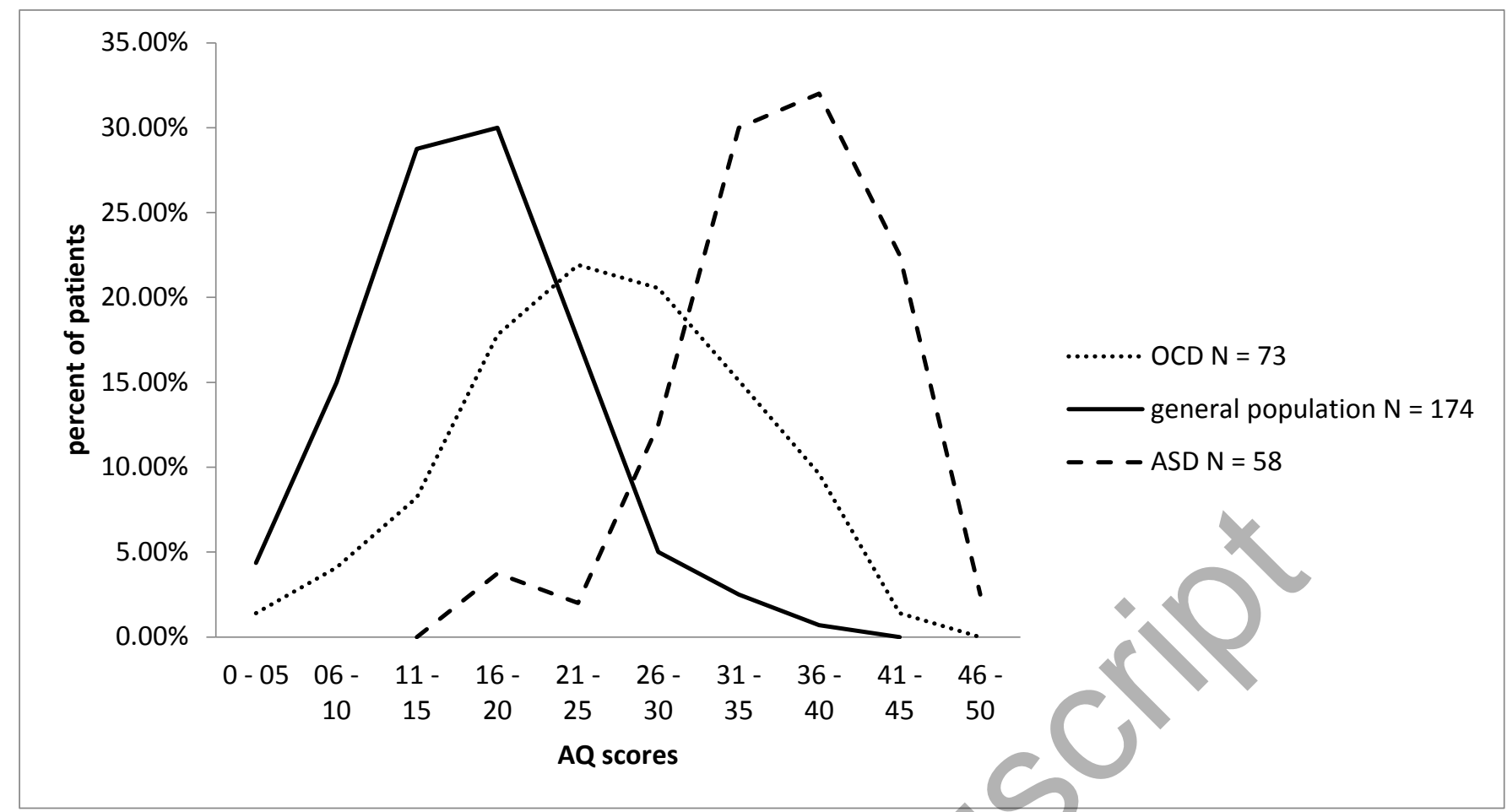

Figure 2 Distribution of total AQ scores in the OCD sample (......), compared to published AQ data from the general population (unbroken line) and high functioning ASD control groups (-------) derived from a published study (Baron-Cohen et al., 2001)

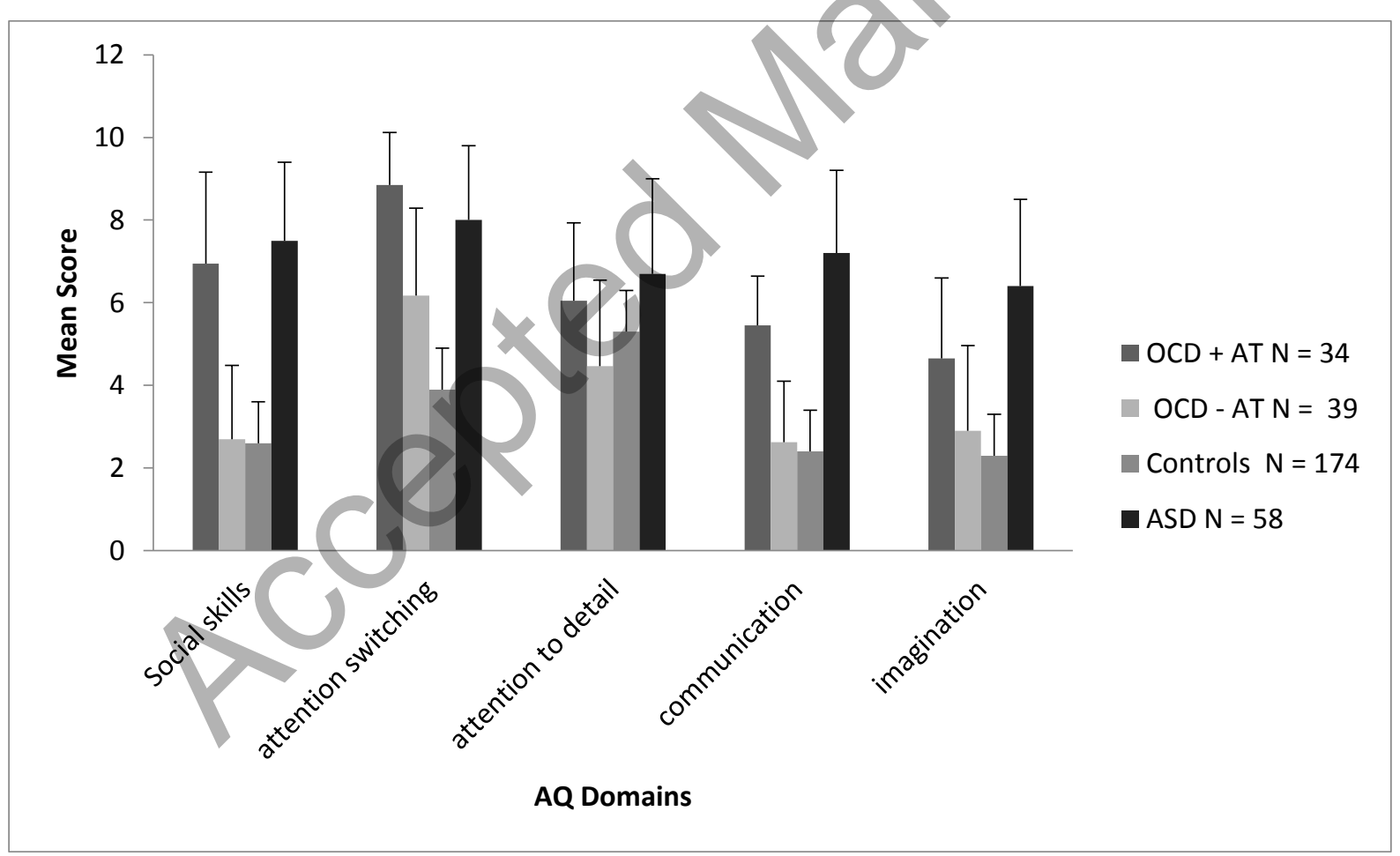

Figure 3. Profile of $A Q$ domains affected in $O C D$ patients with autistic traits 